\title{
Fact or Fiction: The Need for Independent Pharmaceutical Policy Research
}

\author{
Salomeh Keyhani, $M D, M P H^{1,2,3}$ and Alex Federman, $M D, M P H^{3}$ \\ 'James J. Peters Veterans Administration Medical Center, Bronx, NY, USA; ${ }^{2}$ Department of Health Policy, Mount Sinai School of Medicine, \\ New York, NY, USA; ${ }^{3}$ Division of General Internal Medicine, Mount Sinai School of Medicine, New York, NY, USA.
}

$\mathrm{J}$ Gen Intern Med (24)5:692-4

DOI: $10.1007 / \mathrm{s} 11606-009-0964-2$

(c) Society of General Internal Medicine 2009

$\mathrm{S}$ enator Daniel Patrick Moynihan once famously said that people are entitled to their own opinions not their own facts. However, these days it seems that industry or think tanks can produce literature either in the form of research or expert opinion and then rely on the media and policymakers to repeat them to the point that they become well-known facts. For example, it is "well known" that the cost of creating a new drug is \$802 million dollars. ${ }^{1}$ However, fewer people realize that this cost estimate for drug development is based on a nonrandom sample of ten companies for which the data is proprietary and thus not accessible by independent researchers. $^{2}$ Furthermore, the research center that issues such reports is mainly funded by the pharmaceutical industry which would give most consumers of this research reason to pause. There are many such examples in the pharmaceutical policy arena. For example, it is "well known" that if drug prices were reduced pharmaceutical innovation in the US would be adversely affected. The domestic policy concern about preserving innovation has even affected US trade relations-the US government has insisted on national formulary changes in Australia and South Korea to ensure sustained innovation. ${ }^{3,4}$ However, to our knowledge no study has specifically compared innovation between pharmaceutical manufacturers in the US and other countries, nor proven that Australia's evidence based formulary, for example, has adversely affected innovation. Repetition and dissemination appear to create "facts."

In this issue of JGIM, Baker and Fugh-Berman review the research of Dr. Frank Lichtenberg. ${ }^{5}$ Dr. Lichtenberg is an influential health economist whose research focuses on the impact of newer drugs on health, productivity, and spending. His work has been published in a number of peer-reviewed journals, cited in the lay press and congressional documents, and has been widely disseminated on the Internet. ${ }^{6-10}$ Baker and Fugh-Berman's critique pertains to a 2007 study by Lichtenberg that addresses the question of whether newer drugs have a greater impact on increasing life expectancy and decreasing morbidity compared to older drugs (newer vs. older "vintage" drugs, as Lichtenberg terms them). Their Perspectives piece describes critical flaws in Lichtenberg's methods and interpretation of his findings, including omission of key

Published online April 3, 2009 confounding variables, the attribution of improved health outcomes to newer drugs based on cross-sectional analysis (where reverse causation is likely to explain much of the observed effects), and unexplained observations that counter well-established associations between socioeconomic status and health outcomes. Baker and Fugh-Berman also note that Lichtenberg's approach fails to meet the rubric of common clinical sense because he aggregates a wide range of drug classes, from acne medications and proton pump inhibitors to cardiovascular and HIV drugs, and examines their combined impact on mortality. This one-size-fits-all analytic approach necessarily ignores critical, disease-specific confounding factors.

Although Baker and Fugh-Berman's critique is narrow in its scope-focusing on one study by a single investigator-it effectively brings to light the major challenges for both pharmaceutical policy and the care of patients: seeing clearly through the haze of "facts" promoted by the industry and other vested interests that are used to protect drug prices, and identifying the best and most cost-effective therapies for medical conditions.

The debate on innovation, drug reimportation, cost of developing new drugs, and whether other countries "are paying for their fair share of innovation" are all centered on the issue of how health care reform will impact drug prices, an issue of critical concern to the pharmaceutical industry. This type of policy research helps advance the case that any reduction in drug prices will adversely impact innovation and, consequently, our health. Lichtenberg's work is important to the industry because it helps advance the argument that new drugs, while costly, are paying for themselves. He has argued, for example, that the Veterans Administration formulary has a detrimental effect on veteran life expectancy because it restricts access to newer medications, ${ }^{11}$ although published data contradicts this claim and demonstrates that as a system the VA delivers higher quality care compared to private plans and has a lower mortality rate. ${ }^{12-16}$ His work also helps thwart policy proposals aimed at improving the affordability of medications to public insurers or patients. Much of Lichtenberg's work, such as his VA formulary study, has been disseminated through conservative, free-market oriented think tanks like the Manhattan Institute, the Cato Institute, and the American Enterprise Institute. ${ }^{9,10,17}$ These entities are generally unreceptive to health care reform efforts that favor expansion of public insurance programs. The interests of the pharmaceutical industry and these think tanks tend to coalesce around the notion of the importance of a free market place for drugs and the detrimental effects of the monopsony power of public programs on drug prices. Research that supports the contention that public insurance programs adversely impact health fit well with the conservative/libertar- 
ian agenda. This type of selective promotion of research, which bypasses peer review, ignores conflicting research, and is used to support ideological positions, is not exclusive to one side of the ideological spectrum. However, given the resources of the pharmaceutical industry and limited federal funding, pharmaceutical policy debates seem to be particularly dominated by opinion, and non-peer reviewed and/or industry funded research. In the early 1990s the Office of Technology and Assessment was an important arbiter of fact versus fiction. Today, no such congressional agency exists that can provide unbiased filtered analysis to policymakers. ${ }^{18}$

The larger national pharmaceutical policy debates not withstanding, the challenge of disentangling the promotion of ideology or marketing from research also has implications for clinical practice. The last several years have witnessed several insidious cases of drug promotion that even evaded the scrutiny of reviewers and editors of major medical journals. Ghostwriting scandals ${ }^{19-21}$ plagued the VIGOR ${ }^{22}$ and ADVAN$\mathrm{TAGE}^{23}$ trials which understated the risks of rofecoxib, and selective publishing of positive results may have led to overstatements regarding the efficacy of selective serotoninreuptake inhibitors (SSRI) ${ }^{24}$ where industry's decision to silence null studies distorted clinicians' beliefs about the efficacy of these commonly prescribed medications. The line between research and marketing has been blurred to the point that industry sponsored studies should be considered by clinicians with a hefty grain of salt.

Unfortunately, as practicing physicians and clinical educators we face the twin problem of a dearth of unbiased comparative effectiveness research and widespread dissemination of non-peer reviewed information about prescription drugs. Rofecoxib was withdrawn from the market and rosiglitazone received a black box warning from the FDA, but only after tens of millions of prescriptions were dispensed for both thanks to the generously-funded and aggressive advertising campaigns of their manufacturers. Similarly, the use of ezetimibe, a new and more expensive cholesterol reducing medication, has grown to $15 \%$ of the cholesterol lowing drug market in the US despite the availability of inexpensive generic alternatives and lack of evidence of clinical superiority. ${ }^{25,26}$ In all these cases, a new drug was heavily promoted, side effects understated or efficacy was overblown. Lichtenberg makes a general claim that new drugs improve life expectancy, but recent events suggest that new may not always be better. Unfortunately for patients and providers, the slow pace of science and/or lack of focused investment in comparative effectiveness research usually means that as a society we pay for expensive brand name medications more often than we ought to, and often use them heavily only to later discover that existing drugs are as effective and/or safer.

To ensure a more value-based approach to prescription drug spending, unbiased information is needed both to address basic comparative effectiveness questions and to inform important policy debates. A number of researchers and health care advocates have supported the development of a national center for comparative effectiveness which would address the dearth of good information on drugs. ${ }^{27}$ Not surprisingly, while the pharmaceutical industry is quick to claim that new drugs save lives, they have not enthusiastically embraced the development of such a national center. It is always easier to claim improvements in health rather than prove them. However, in addition to the need for unbiased information on drugs, policymakers also require unbiased policy analysis. Otherwise, interested parties across the political spectrum can find and selectively and aggressively disseminate research that supports their positions. Absent serious public investment in comparative effectiveness research and pharmaceutical policy analysis disentangling fact versus fiction will continue to remain a challenge both to clinicians and policymakers.

Funding/Support/Financial Disclosures: This project was not directly supported by any external grants or funds. Drs. Keyhani and Federman are supported by grants from the VA HSR\&D Service and the National Institute on Aging.

Corresponding Author: Salomeh Keyhani, MD, MPH, Department of Health Policy, Mount Sinai School of Medicine, Box 1077, 1 Gustave L. Levy Place, New York, NY 10029, USA (e-mail: salomeh. keyhani@mountsinai.org).

\section{REFERENCES}

1. DiMasi JA. The price of innovation: new estimates of drug development costs. J Health Econ. 2003;22:151-85.

2. Light DW, Warburton RN. Extraordinary claims require extraordinary evidence. J Health Econ. 2005;24(5):1030-3; discussion 1034-1053.

3. Doran E, Alexander Henry D. Australian pharmaceutical policy: price control, equity, and drug innovation in Australia. J Public Health Policy. 2008;29(1):106-20.

4. Yang BM, Bae EY, Kim J. Economic evaluation and pharmaceutical reimbursement reform in South Korea's National Health Insurance. Health Aff (Millwood). 2008;27(1):179-87.

5. Baker D, Fugh-Berman A. Do new drugs increase life expectancy? A critique of a Manhattan Institute paper. J Gen Intern Med. 2009.

6. Issues in Designing a Prescription Drug Benefit for Medicare. In: Office CB, ed; 2002.

7. Lichtenberg FR. Yes, New Drugs Save Lives. Washington Post, 2007.

8. Barru T. New York Leads States in Longevity Gain, Study Says: Bloomberg News; 2007

9. Bandow D. High Prices for Medication Are a Blessing for the Sick. http:// www.cato.org/pub display.php?pub_id=3596. Accessed Dec 12, 2008.

10. Lichtenberg FR. Why Has Longevity Increased More in Some States than in Others? The Role of Medical Innovation and Other Factors In: Research MIfP, ed; 2007.

11. Tanner M. You Say You Want VA-Style Health Care? http://www.cato. org/pub_display.php?pub_id=8138. Accessed Dec 11, 2008.

12. Barnett MJ, Perry PJ, Langstaff JD, Kaboli PJ. Comparison of rates of potentially inappropriate medication use according to the Zhan criteria for VA versus private sector medicare HMOs. J Manag Care Pharm. 2006; 12(5):362-70.

13. Busch SH, Leslie DL, Rosenheck RA. Comparing the quality of antidepressant pharmacotherapy in the Department of Veterans Affairs and the private sector. Psychiatr Serv. 2004;55(12):1386-91.

14. Piette JD, Heisler M. Problems due to medication costs among VA and nonVA patients with chronic illnesses. Am J Manag Care. 2004;10(11 Pt 2):861-8.

15. Keyhani S, Ross JS, Hebert P, Dellenbaugh C, Penrod JD, Siu AL. Use of preventive care by elderly male veterans receiving care through the Veterans Health Administration, Medicare fee-for-service, and Medicare HMO plans. Am J Public Health. 2007;97(12):2179-85.

16. Selim AJ, Kazis LE, Rogers W, et al. Risk-adjusted mortality as an indicator of outcomes: comparison of the Medicare Advantage Program with the Veterans' Health Administration. Med Care. 2006;44(4):359-65.

17. Lichtenberg FR. The Allocation of Public Funds for Biomedical R\&D. Washington DC 1999.

18. Pharmaceutical Research and Development: Costs, Risks and Rewards. Washington, D.C.: U.S. Congress, Office of Technology Assessment; 1993.

19. Daskalopoulou SS, Mikhailidis DP. Exorcising ghosts and unwelcome guests. Ann Intern Med. 2006;144(2): 149.

20. Hill KP, Ross JS, Egilman DS, Krumholz HM. The ADVANTAGE seeding trial: a review of internal documents. Ann Intern Med. 2008;149(4):251-8. 
21. Ross JS, Hill KP, Egilman DS, Krumholz HM. Guest authorship and ghostwriting in publications related to rofecoxib: a case study of industry documents from rofecoxib litigation. JAMA. 2008;299(15):1800-12.

22. Bombardier C, Laine L, Reicin A, et al. Comparison of upper gastrointestinal toxicity of rofecoxib and naproxen in patients with rheumatoid arthritis. VIGOR Study Group. N Engl J Med. 2000;343 (21):1520-8. $1522 \mathrm{p}$ following 1528.

23. Lisse JR, Perlman M, Johansson G, et al. Gastrointestinal tolerability and effectiveness of rofecoxib versus naproxen in the treatment of osteoarthritis: a randomized, controlled trial. Ann Intern Med. 2003;139(7):539-46.
24. Kirsch I, Deacon BJ, Huedo-Medina TB, Scoboria A, Moore TJ, Johnson BT. Initial Severity and Antidepressant Benefits: A MetaAnalysis of Data Submitted to the Food and Drug Administration. PLoS Medicine. 2008;5(2):e45.

25. Kastelein JJP, Akdim F, Stroes ESG, et al. Simvastatin with or without Ezetimibe in Familial Hypercholesterolemia. N Engl J Med. 2008;358 (14):1431-3.

26. Drazen JM, Jarcho JA, Morrissey S, Curfman GD. Cholesterol Lowering and Ezetimibe. N Engl J Med. 2008;358(14):1507-8.

27. Wilensky GR. Developing A Center For Comparative Effectiveness Information. Health Aff. 2006;25(6):w572-85. 